\title{
Development of high performance catalysts for CO oxidation using data-based modeling
}

\author{
Wenjin Yan ${ }^{\mathrm{a}}$, Yuanting Chen ${ }^{\mathrm{a}}$, Yanhui Yang ${ }^{\mathrm{a}, *}$, Tao Chen ${ }^{\mathrm{a}, \mathrm{b}, *}$ \\ ${ }^{a}$ School of Chemical and Biomedical Engineering, Nanyang Technological University, 62 Nanyang \\ Drive, Singapore 637459, Singapore \\ ${ }^{b}$ Division of Civil, Chemical and Environmental Engineering, University of Surrey, Guildford GUQ \\ $7 X H, U K$
}

\begin{abstract}
This paper presents a model-aided approach to the development of catalysts for CO oxidation. This is in contrast to the traditional methodology whereby experiments are guided based on experience and intuition of chemists. The proposed approach operates in two stages. To screen a promising combination of active phase, promoter and support material, a powerful "space-filling" experimental design (specifically, Hammersley sequence sampling) was adopted. The screening stage identified $\mathrm{Au}-\mathrm{ZnO} / \mathrm{Al}_{2} \mathrm{O}_{3}$ as a promising recipe for further optimization. In the second stage, the loadings of $\mathrm{Au}$ and $\mathrm{ZnO}$ were adjusted to optimize the conversion of $\mathrm{CO}$ through the integration of a Gaussian process regression (GPR) model and the technique of maximizing expected improvement. Considering that $\mathrm{Au}$ constitutes the main cost of the catalyst, we further attempted to reduce the loading of Au with the aid of GPR, while keeping the low-temperature conversion to a high level. Finally we obtained $2.3 \% \mathrm{Au}$ $5.0 \% \mathrm{ZnO} / \mathrm{Al}_{2} \mathrm{O}_{3}$ with 21 experiments. Infrared reflection absorption spectroscopy and hydrogen temperature-programmed reduction confirmed that $\mathrm{ZnO}$ significantly promotes the catalytic activity of $\mathrm{Au}$.
\end{abstract}

Keywords: Carbon monoxide oxidation, Design of experiments, Heterogeneous catalysis, Model-aided process optimization, Model uncertainty, Response surface methodology

\section{Introduction}

CO is a highly noxious gas that needs to be removed, usually through catalytic oxidation, in many applications, such as gas masks, indoor air quality control systems and automobile exhaust treatment devices. CO is also known to deactivate the electrocatalysts in hydrogen fuel cells [1]. In addition, CO oxidation is regarded as a general

\footnotetext{
${ }^{*}$ Corresponding authors. Tel.: +44 1483 686593, Fax: +44 1483686581 (T. Chen).

Email addresses: yhyang@ntu.edu.sg (Yanhui Yang), t.chen@surrey.ac.uk (Tao Chen)
} 
reaction for investigating the activity of oxidation catalysts [2]. Low-temperature activity is preferred in this study, since low-temperature reaction is environmentally friendly and cost effective in terms of equipment requirements.

The catalysts that have been developed for CO oxidation so far may be classified into two categories: (1) noble metal catalysts and (2) transition metal oxide catalysts [3]. Noble metal catalysts often use $\mathrm{Pt}, \mathrm{Ru}, \mathrm{Rh}, \mathrm{Pd}$ or $\mathrm{Au}$ as active phase, with support materials ranging from $\mathrm{Al}_{2} \mathrm{O}_{3}, \mathrm{SiO}_{2}$, zeolite and $\mathrm{CeO}_{2}$. A few catalysts were demonstrated to present high activity, such as $\mathrm{Ru} / \mathrm{Al}_{2} \mathrm{O}_{3}$ [4], $\mathrm{Rh} / \mathrm{Al}_{2} \mathrm{O}_{3}$ [5], $\mathrm{Au}-\mathrm{ZnO} / \mathrm{SiO}_{2}$ [6], $\mathrm{Au} / \mathrm{TiO}_{2}$ [7] and $\mathrm{Pt} / \mathrm{Al}_{2} \mathrm{O}_{3}$ [8]. Transition metal catalysts have great potential due to the low cost, though their performance is generally inferior to that of the noble metals. $\mathrm{Co}_{3} \mathrm{O}_{4}[9], \mathrm{MoO}_{3} / \mathrm{CeO}_{2}[10]$ and $\mathrm{CuO} / \mathrm{CeO}_{2}$ [11] are the most important transition metal catalysts with demonstrated high activity. In addition, $\mathrm{CuO}$ was shown as a cost-effective active phase in $\mathrm{CuO}-\mathrm{CeO}_{2} / \mathrm{Al}_{2} \mathrm{O}_{3}[12]$ and $\mathrm{CuO}-\mathrm{ZnO} / \mathrm{TiO}_{2}$ [13] catalysts.

Currently, the development of catalysts is usually based on experiments under the guidance of experience and intuition of chemists. In the presence of multiple factors that affect the activity, usually one factor is varied with other factors being fixed for conducting experiments. Subsequently, this procedure is repeated for each factor to search for the "optimal" performance. This one-factor-at-a-time method has long been recognized as ignorant of the correlation between factors, resulting in ineffective exploration of the factors' space [14]. As a result, a more rational and systemic approach, based on mathematical models, is needed for the design and optimization of catalysts.

Data-based models (also termed empirical models) play an important role in modelaided catalyst development and interpretation [15, 16, 17, 18]. They are developed purely based on experimental data, with the possibility to incorporate prior knowledge (though not compulsory). Due to limited experimental resources, the procedure for developing a new catalyst usually includes two stages: screening for metal/support combinations and then adjusting the loading of the components. The statistical method of design of experiments (DoE) can be applied to the screening step with limited experiments. At the second stage, DoE, data-based modeling and mathematical optimization approaches can be applied to adjust the loading of catalyst components (and sometimes the reaction conditions). This model-aided technique is also termed response surface methodology (RSM) [14].

The general model-aided process design has been investigated in recent years with emerging applications in catalysis [19, 20, 21, 17, 22, 23, 24, 25, 26, 27]. The main components in these previous reports include quantitative property activity relationship (QSAR), genetic algorithms (GA) and artificial neural network (ANN), generally based on high-throughput experimentation (HTE). When HTE is not available (as in our laboratory) and thus nor are the large amount of data, the principle of QSAR and the use of ANN may be questionable [28].

In the current study, we integrate several state-of-the-art computational methods to search for optimal catalysts for $\mathrm{CO}$ oxidation. The catalyst screening stage was facilitated by the application of Hammersley sequence sampling, a space-filling DoE method that has been shown to provide better coverage of design space than traditional DoE 
methods [29]. The screening experiments suggested to focus on $\mathrm{Au}-\mathrm{ZnO} / \mathrm{Al}_{2} \mathrm{O}_{3}$, a catalyst that has not be intensively investigated previously for $\mathrm{CO}$ oxidation. To further optimize the catalyst performance, a Gaussian process regression (GPR) model is developed from experimental data to relate the $\mathrm{CO}$ conversion to the loadings of $\mathrm{Au}$ and $\mathrm{ZnO}$. GPR has been shown to attain both accurate prediction and reliable quantification of its own prediction uncertainty (in terms of variance) [30, 31]. The latter property is especially important for our model-aided optimization strategy, namely maximization of expected improvement (EI), since a large variance suggests that the experimental data around this point are not sufficient to give a reliable prediction and thus more experiments should be allocated. The criterion of EI jointly considers the predictive mean and variance leading to a theoretically guaranteed global optimum [32]. The effectiveness of the optimization methods, in particular the use of GPR and EI, has been demonstrated elsewhere through both experiments and computer simulations $[30,31,32]$. This work is the first to report the application of such an integrated framework for the optimization of catalysis systems. The proposed approach successfully identified a high-performance catalyst $4.9 \% \mathrm{Au}-5.0 \% \mathrm{ZnO} / \mathrm{Al}_{2} \mathrm{O}_{3}$. The other contribution of this paper is to demonstrate that the GPR model can also be used to help reduce the loading of $\mathrm{Au}$ with marginal deterioration of catalyst activity, a strategy to reduce the cost of catalyst.

This is a powerful tool to aid the decision with regard to the compromise between performance and cost in practice.

\section{Experimental}

\subsection{Catalyst preparation}

Catalysts were prepared by the single-step co-precipitation method [33]. First, certain amount of corresponding precursors of active phase (noble metal), promoter (metal oxide) and support (another metal oxide) were loaded into a round-bottomed flask (capacity: $50 \mathrm{ml}$ ), followed by adding sufficient amount of urea and $20 \mathrm{ml}$ of deionized (DI) water. The mixture was gradually heated to $90{ }^{\circ} \mathrm{C}$ and maintained for $6 \mathrm{~h}$ under continuous agitation by magnetic stirrer. Subsequently, the flask was cooled down to room temperature and aged overnight. The precipitate was filtered, thoroughly washed with DI water for three times, and then dried at $100{ }^{\circ} \mathrm{C}$ overnight. The ground powder was then calcined in air at $300{ }^{\circ} \mathrm{C}$ for $4 \mathrm{~h}$ (the calcination temperature was reached from room temperature with a heating rate of $2{ }^{\circ} \mathrm{C} \cdot \mathrm{min}^{-1}$ ). Finally, the calcined sample was naturally (without control) cooled to room temperature.

\subsection{Catalyst characterization}

X-ray diffraction (XRD) patterns were obtained by a Bruker D8 advance powder diffractometer equipped with a monochromatic $\mathrm{Cu}-\mathrm{K} \alpha$ radiation source (lambda $=$ $0.15406 \mathrm{~nm}$ ), operating at $40 \mathrm{kV}$ and $40 \mathrm{~mA}$. Diffraction data were collected in the range of $2 \theta$ from $10^{\circ}$ to $80^{\circ}$ with a resolution of $0.05^{\circ}(2 \theta)$. 
Nitrogen physiorption isotherms were carried out on a Quantachrome Autosorb-6b static volumetric instrument. The calcined samples were degassed at $250{ }^{\circ} \mathrm{C}$ under high vacuum for $3 \mathrm{~h}$ prior to the adsorption-desorption isotherm measurement at -196 ${ }^{\circ} \mathrm{C}$. The specific surface area was estimated by the five-point BET method.

The in-situ infrared reflection absorption spectroscopy (IRAS) was collected on a PerkinElmer Spectrum One FT-IR spectrometer using CO as probe molecules. The sample was mixed with $\mathrm{KBr}$ in a 1:2 mass ratio then pressed into pellet. The pellet was then placed into an in-situ IR cell with $\mathrm{CaF}_{2}$ windows. A thermal pretreatment was conducted in He flow at $250{ }^{\circ} \mathrm{C}$ for $2 \mathrm{~h}$ with a heating rate of $2{ }^{\circ} \mathrm{C} \cdot \mathrm{min}^{-1}$ to remove the moisture. After cooled down to room temperature, the sample cell was switched to pure CO flow $(99.5 \%)$ and maintained for $0.5 \mathrm{~h}$. The adsorption spectra were recorded at room temperature with parameters: $4000-900 \mathrm{~cm}^{-1}$, resolution of $1 \mathrm{~cm}^{-1}$, and scan for $1 \mathrm{~min}$.

The reducibility of the sample was investigated by hydrogen temperature-programmed reduction $\left(\mathrm{H}_{2}\right.$-TPR) using Autosorb-1C (Quanta Chrome), equipped with a thermal conductivity detector (TCD). Before running the $\mathrm{H}_{2}-\mathrm{TPR}, 300 \mathrm{mg}$ of the sample was loaded in a quartz reactor, pretreated by ultra zero grade air at $300{ }^{\circ} \mathrm{C}$ for $1 \mathrm{~h}$ and then cooled down to room temperature to form a clean surface. Thereafter, the gas flow was switched to 5 vol.\% hydrogen with argon balance and the baseline was monitored until stable. After baseline stabilization, the sample cell was heated to $1000{ }^{\circ} \mathrm{C}$ with a heating rate of $10{ }^{\circ} \mathrm{C} \cdot \min ^{-1}$ and kept for $1 \mathrm{~h}$ to ensure complete reduction.

Transmission electron microscopy (TEM) was conducted on a JEOL JEM-2010 operated at $200 \mathrm{kV}$. The samples were suspended in ethanol and dried on holey carboncoated $\mathrm{Cu}$ grids before observation.

\subsection{Activity test}

The catalytic activity was evaluated in a fixed-bed flow reactor. The pretreatment was conducted in a gas mixture of $\mathrm{H}_{2}\left(6 \mathrm{ml} \mathrm{min}^{-1}\right)$ and $\mathrm{He}\left(20 \mathrm{ml} \mathrm{min}^{-1}\right)$ at $300{ }^{\circ} \mathrm{C}$ for $3 \mathrm{~h}$. One hundred $\mathrm{mg}$ of catalyst was used for each test with the gas flow mixed of $\mathrm{CO}\left(2 \mathrm{ml} \mathrm{min}{ }^{-1}\right), \mathrm{O}_{2}\left(10 \mathrm{ml} \mathrm{min}{ }^{-1}\right)$ and $\mathrm{He}\left(100 \mathrm{ml} \mathrm{min}^{-1}\right)$. The composition of the effluent gas was analyzed using an online GC-6890N (Agilent Technologies) equipped with a $10 \mathrm{ft} \times 1 / 8$ in $\times 2.1 \mathrm{~mm}$ 100/120 Carbosieve SII column. The CO conversion was calculated on a molar basis.

\section{Data-based modeling and model-aided optimization}

The proposed model-aided catalyst design methodology includes the following three components:

1. DoE to allocate appropriate initial experiments for catalyst screening.

2. Development of an empirical model from the experimental data.

3. Model-based optimization to search for next-iteration experiment(s) that give (predicted) maximal conversion. 
This is an iterative approach and should terminate when the improvement of catalyst performance becomes small. A brief overview of these components is given in the rest of this section.

\subsection{Design of Experiments}

DoE is widely used to allocate experimental points for data-based modeling, since it provides good coverage in the factors space and results in a more accurate model. In model-aided catalyst design, DoE can be applied to help screen catalysts in terms of metal/support combinations, as well as to design experiments for optimizing the loading of components and reaction conditions.

Based on the randomization, replication and blocking principles of DoE, the classical fractional factorial and central composite designs were proposed to estimate the correlation between process factors based on polynomial models [14]. Typically, two or three pre-determined levels are assigned for each process factor, and then experiments are conducted at the combinations of the levels of these factors. Factorial designs are favorable in simple cases in which the factors are difficult to change. Nevertheless, these approaches perform poorly in complex processes due to limited levels of the factors being studied, giving a less reliable data-based model [34]. The recognition of this disadvantage of classical DoEs has motivated the concept of "space-filling" designs that allocate design points to be uniformly distributed within the range of each factor [34].

One straightforward space-filling design is to generate Monte Carlo random samples, which requires a large number of experiments. To overcome this problem, stratified and deterministic sampling methods have been investigated to provide a good coverage of the input space with minimal number of design points, such as Latin hypercube sampling (LHS) [35], uniform design (UD) [34] and Hammersley sequence sampling (HSS) [29]. In this study, the HSS design is adopted, because it has been shown to attain improved uniformity over random sampling and LHS, and its implementation is significantly easier than that of UD. In addition, empirical comparison demonstrated that HSS and UD usually achieve comparable results [36].

The basis of HSS design is that any integer $n$ can be rewritten in a radix notation of another integer $R$ as follows:

$$
\begin{aligned}
n & \equiv n_{0} n_{1} n_{2} \cdots n_{m-1} n_{m} \\
& =n_{m}+n_{m-1} R+n_{m-2} R^{2}+\cdots+n_{1} R^{m-1}+n_{0} R^{m}
\end{aligned}
$$

where $m$ is the integer part of $\log _{R} n$. A function of $n$, defined as inverse radix number, can be constructed by reversing the order of the digits of $n$ and concatenating them behind a decimal point:

$$
\begin{aligned}
\psi_{R}(n) & =0 . n_{m} n_{m-1} \cdots n_{2} n_{1} n_{0} \\
& =n_{m} R^{-1}+n_{m-1} R^{-2}+\cdots+n_{1} R^{-m}+n_{0} R^{-m-1}
\end{aligned}
$$


Therefore, if $n$ design points, each being a vector of dimension $d$, need to be allocated by HSS design, the first $d-1$ prime numbers should be selected as the integer $R$ in Eq. (1): $R_{1}, R_{2}, \cdots, R_{d-1}$. The design points are given by

$$
\mathbf{x}_{i}=\mathbf{1}-\left[\frac{i}{n}, \psi_{R_{1}}(n), \psi_{R_{2}}(n), \cdots, \psi_{R_{d-1}}(n)\right]^{\mathrm{T}}
$$

where $i=1,2, \cdots, n$ and $\mathbf{1}$ is a unity vector.

\subsection{Gaussian process regression}

GPR, originally initiated in the statistical community, has gained significant attention as a powerful modeling tool for general scientific and engineering tasks [30, 31, 37, 38]. Compared with other popular modeling methods like ANN, GPR has been demonstrated to give more reliable predictive performance [31, 39]. In addition, the Bayesian origin of GPR automatically provides the uncertainty (variance) of prediction, which is indispensable to robust model-aided optimization [30, 31, 32]. In this study, GPR was implemented to develop a data-based model to relate the $\mathrm{CO}$ conversion to $\mathrm{Au}$ and $\mathrm{ZnO}$ loadings, and it formed the basis of model-based optimization.

Specifically, GPR aims at relating the scalar process response $y$ to the $d$-dimensional factor $\mathbf{x}$. Given a set of experimental data of size $n:\left\{\mathbf{x}_{i}, y_{i} ; i=1, \ldots, n\right\}$, a GPR is defined such that the regression function $y(\mathbf{x})$ has a Gaussian prior distribution with zero mean, or in discrete form:

$$
\mathbf{y}=\left(y_{1}, \ldots, y_{n}\right)^{\mathrm{T}} \sim G(\mathbf{0}, \mathbf{C})
$$

where $\mathbf{C}$ is an $n \times n$ covariance matrix, whose $i j$-th element is defined by a covariance function: $\mathbf{C}_{i j}=C\left(\mathbf{x}_{i}, \mathbf{x}_{j}\right)$. A widely used covariance function is:

$$
C\left(\mathbf{x}_{i}, \mathbf{x}_{j}\right)=a_{0}+a_{1} \sum_{k=1}^{d} x_{i k} x_{j k}+v_{0} \exp \left(-\sum_{k=1}^{d} w_{k}\left(x_{i k}-x_{j k}\right)^{2}\right)+\sigma^{2} \delta_{i j}
$$

where $x_{i k}$ is the $k$-th variable of $\mathbf{x}_{i} ; \delta_{i j}=1$ if $i=j$, otherwise $\delta_{i j}=0$. The covariance function is parameterized by $\boldsymbol{\theta}=\left(a_{0}, a_{1}, v_{0}, w_{1}, \ldots, w_{d}, \sigma^{2}\right)^{\mathrm{T}}$, which is termed "hyperparameters" due to the origin in Bayesian non-parametric statistics. As such, GPR may also be derived from the principle of Bayesian non-parametric regression; see [39] for more details together with discussion of other forms of covariance functions.

For a new data point with factor $\mathbf{x}^{*}$, the predicted response $y$ also follows a normal distribution, of which the mean $\left(\hat{y}^{*}\right)$ and variance $\left(\sigma_{\hat{y}^{*}}^{2}\right)$ are

$$
\begin{aligned}
\hat{y}^{*} & =\mathbf{k}^{\mathrm{T}}\left(\mathbf{x}^{*}\right) \mathbf{C}^{-1} \mathbf{y} \\
\sigma_{\hat{y}^{*}}^{2} & =C\left(\mathbf{x}^{*}, \mathbf{x}^{*}\right)-\mathbf{k}^{\mathrm{T}}\left(\mathbf{x}^{*}\right) \mathbf{C}^{-1} \mathbf{k}\left(\mathbf{x}^{*}\right)
\end{aligned}
$$

where $\mathbf{k}\left(\mathbf{x}^{*}\right)=\left[C\left(\mathbf{x}^{*}, \mathbf{x}_{1}\right), \ldots, C\left(\mathbf{x}^{*}, \mathbf{x}_{n}\right)\right]^{\mathrm{T}}$. 
The hyper-parameters can be estimated by maximizing the logarithm of the likelihood function defined in Eq. (4): $L=\log p(\mathbf{y} \mid \boldsymbol{\theta}, \mathbf{X})$. A Matlab implementation of GPR, based on the conjugate gradient method, is publicly available from http: //www.gaussianprocess.org/gpml/code/matlab/doc/ [39], and it is used in this study. In addition, to ensure numerical stability, the data may be linearly transformed to the range of $[-1,1]$ at each process factor.

\subsection{Model-based optimization}

The developed GPR forms the basis for catalyst optimization. A straightforward method is to find the input $\mathrm{x}^{*}$ that gives the best predicted process response, and then conduct new experiment at $\mathbf{x}^{*}$. Subsequently, the model is updated by including all available data. The procedure continues until the improvement of process response becomes smaller than a threshold. However, this approach ignores the fact that model prediction is not perfect and carries uncertainty, which is represented by prediction variance of GPR. A large variance suggests that the experimental data around this point are not sufficient to give a reliable prediction. Therefore, both predictive mean and variance must be jointly considered in the optimization algorithm. Otherwise, the algorithm is likely to find only a local, not global, optimum [32]. In the literature, a few methods have been suggested to handle prediction uncertainty, including maximization of lower or upper prediction bound [30,31], minimization of information free energy [40], maximization of relative information gain [41], and maximization of expected improvement (EI) [32]. The criterion of EI incorporates the predictive mean and variance in a rigorous statistical framework, as opposed to user-determined weighting of the impact of mean and variance in other methods. Therefore, EI is adopted in this study to identify the loading of components that are likely to improve the process response and/or prediction accuracy.

Specifically, let $y(\mathbf{x})$ be the prediction at $\mathbf{x}$ from a GPR model. For a maximization problem, the predicted improvement over the best response obtained through experiments so far (denoted $f_{\text {best }}$ ) at $\mathbf{x}$ is thus $I(\mathbf{x})=y(\mathbf{x})-f_{\text {best }}$. Since $y(\mathbf{x})$ is Gaussian distributed with mean $\hat{y}$ and variance $\sigma_{\hat{y}}^{2}$, the improvement $I(\mathbf{x})$ is also Gaussian distributed with mean $\hat{y}-f_{\text {best }}$ and the same variance. Therefore, the expectation of improvement at $\mathbf{x}$ is [32]:

$$
\begin{aligned}
\operatorname{EI}(\mathbf{x}) & =E[\max \{0, I(\mathbf{x})\}]=\int_{0}^{\infty} I p(I) \mathrm{d} I \\
& =\sigma_{\hat{y}}[u \Phi(u)+\phi(u)]
\end{aligned}
$$

where $u=\left(\hat{y}-f_{\text {best }}\right) / \sigma_{\hat{y}}, \Phi(\cdot)$ and $\phi(\cdot)$ denote the cumulative distribution function and density function of standard normal distribution, respectively. Note that both $\hat{y}$ and $\sigma_{\hat{y}}$, obtained from the prediction using the GPR, are functions of process factors $\mathbf{x}$. Thus EI is also a function of $\mathbf{x}$. EI will increase if the mean prediction is greater than $f_{\text {best }}$ and/or the predictive variance is large, and thus further experiments should be conducted at this region. Therefore, we search for process factors $\mathbf{x}$ that maximizes EI, 
a task that can be accomplished by standard mathematical optimization technology (e.g. gradient based methods).

\section{Results and discussion}

\subsection{Catalyst screening}

For the $\mathrm{CO}$ oxidation reaction, the attention was restricted to developing a catalyst whose active phase is a noble metal, promoter is a metal oxide and support is another metal oxide. Based on available resources, four choices were assigned to each component, as given in Table 1. The precursors of these chemicals were also listed in Table 1, while $\mathrm{SiO}_{2}$ was directly purchased (Cab-osil@M5, Riedel-de Haën). In addition, $\left(\mathrm{C}_{4} \mathrm{H}_{9} \mathrm{O}\right)_{4} \mathrm{Ti}$ is titanium n-butoxide and $\left(\mathrm{C}_{5} \mathrm{H}_{8} \mathrm{O}_{2}\right)_{2} \mathrm{Co}$ is cobalt acetylacetonate.

(Table 1 about here)

HSS was applied to allocate 12 experimental points $(n=12)$, with five factors $(d=5)$ : choice of active phase, promoter and support, and the loading of active phase and promoter. The choice of active phase, promoter and support are discrete factors, which can only be assigned to four distinct values, corresponding to four choices of each factor. The range of the two loading factors was set to 1.0 wt.\%-5.0 wt.\%. The 12 experiments designed by HSS are shown in Table 2, which does not include all possible combinations of the three discrete factors, since doing so would require $4 \times 4 \times 4=64$ experiments even with fixed loadings of active phase and promoter. To consider five factors simultaneously, even more experiments are needed and this is not feasible due to the limited resources in this work. In this regard, HSS, and DoE methods in general, may miss some potentially highly active catalysts. Nevertheless, under the same constraint of resources, statistical DoE methods have been shown to be more desirable than the one-factor-at-a-time method [14].

(Table 2 about here)

The catalyst activity is presented in Fig. 1. Since the objective is to find a maximal $\mathrm{CO}$ conversion at low temperature, $\mathrm{Au}-\mathrm{ZnO} / \mathrm{Al}_{2} \mathrm{O}_{3}$ (No. 3 in Table 2) was chosen for further optimization since it performed significantly better than the others.

(Fig. 1 about here)

\subsection{Adjust loading of components}

A GPR model was developed to optimize the loadings of Au (active phase) and $\mathrm{ZnO}$ (promoter) in order to reach a maximal $\mathrm{CO}$ conversion at low temperature. The loadings of active phase and promoter were considered as factors $(\mathbf{x})$ and the activity as response $(y)$. In this case study, activity was defined as the average conversion under $40{ }^{\circ} \mathrm{C}, 60{ }^{\circ} \mathrm{C}$ and $80{ }^{\circ} \mathrm{C}$, as a catalyst with superior low-temperature activity is preferred. Clearly, a single data point $\left(3.4 \% \mathrm{Au}-2.7 \% \mathrm{ZnO} / \mathrm{Al}_{2} \mathrm{O}_{3}\right)$ is not enough to develop a reasonable model. In addition, the interaction between $\mathrm{Au}$ and $\mathrm{ZnO}$ is worthy studying. Hence, two additional catalysts, $1.0 \% \mathrm{Au} / \mathrm{Al}_{2} \mathrm{O}_{3}$ and $5.0 \% \mathrm{Au} / \mathrm{Al}_{2} \mathrm{O}_{3}$, were tested. The resultant activity is shown in Fig. 2. 
(Fig. 2 about here)

With these three data points ${ }^{1}$, a GPR model was developed and EI was applied to search for the next experimental point that has the potential to further improve the activity. The results are summarized in Table 3. The next experiment, $4.9 \% \mathrm{Au}-$ $5.0 \% \mathrm{ZnO} / \mathrm{Al}_{2} \mathrm{O}_{3}$, was selected because it maximized the $\mathrm{EI}(\max (\mathrm{EI})=1.56)$. This catalyst turned out to present close to $100 \%$ conversion at all temperatures between 40 to $220{ }^{\circ} \mathrm{C}$ (thus by above definition its activity is also close to $100 \%$ ). After incorporating this data point to update the GPR model, the maximal value of EI decreased dramatically to $7.57 \times 10^{-5}$, suggesting that further improvement in activity is unlikely and the optimization procedure may terminate. The same conclusion may be reached by observing the almost full CO conversion, and thus it is unlikely to further improve the catalyst activity.

(Table 3 about here)

Considering that $\mathrm{Au}$ is a noble metal and constitutes the main cost of the catalyst, we further attempted to reduce the loading of Au while keeping the conversion under low temperature at a high level. Note that the loading of $\mathrm{ZnO}$ was also considered as a factor instead of being fixed at $5.0 \%$. The following model-aided approach was applied for this purpose:

1. Develop a GPR model using all available data to relate the catalyst activity (response) to the loadings of $\mathrm{Au}$ and $\mathrm{ZnO}$ (factors).

2. Search for the lowest Au-loading that still gives the predicted mean conversion higher than $95 \%$. Conduct experiment to test the actual activity.

3. Use the obtained data to validate the model accuracy. Terminate when the model prediction is close to the actual activity; otherwise go to step 1.

Table 3 (Run 5-10) presents the results by following the above approach. In the entire Au-loading reduction procedure, $\mathrm{ZnO}$ loading was set by the optimization algorithm to the upper bound ( $5 \%$ ), indicating the importance of having sufficient $\mathrm{ZnO}$. The poor prediction at Run 7 is largely because the region of low $\mathrm{Au}$ and high $\mathrm{ZnO}$ loading was not well explored in the previous experiments. This is the fundamental limitation of data-based modeling whereby prediction at unvisited space is poor. However, this is also important information to suggest that more data should be collected around these regions to improve the model. The iterative Au-loading reduction procedure terminated after Run 10 since the actual activity was very close to the prediction, resulting in the desirable catalyst $2.3 \% \mathrm{Au}-5.0 \% \mathrm{ZnO} / \mathrm{Al}_{2} \mathrm{O}_{3}$.

\footnotetext{
${ }^{1} \mathrm{~A}$ more rigorous method is to apply statistical DoE method, e.g. HSS, to allocate initial data points, followed by developing GPR model and model-based optimization. Incidentally, we found in this study that initiating from these three data points resulted in excellent catalyst. In general, rigorous initial DoE should be adopted in practice.
} 
Clearly, the choice of tolerable activity degradation (from $100 \%$ to $95 \%$ ) is rather subjective. The reduction of gold content is at the expense of reduction of activity. Whether this is financially justifiable needs to be carefully examined in practice. Nevertheless, this study demonstrated a viable model-based solution, if the trade-off between catalyst cost and process profit is to be investigated.

To further investigate the interaction between $\mathrm{Au}$ and $\mathrm{ZnO}$, two more catalysts, $2.3 \% \mathrm{Au} / \mathrm{Al}_{2} \mathrm{O}_{3}$ and $5.0 \% \mathrm{ZnO} / \mathrm{Al}_{2} \mathrm{O}_{3}$, were tested (Fig. 3). Clearly, $\mathrm{ZnO}$ significantly promotes the catalytic activity of $\mathrm{Au}$ since $2.3 \% \mathrm{Au}-5.0 \% \mathrm{ZnO} / \mathrm{Al}_{2} \mathrm{O}_{3}$ performs better than $2.3 \% \mathrm{Au} / \mathrm{Al}_{2} \mathrm{O}_{3}$, while $5.0 \% \mathrm{ZnO} / \mathrm{Al}_{2} \mathrm{O}_{3}$ presents very low activity.

(Fig. 3 about here)

\subsection{Characterization}

Three catalyst, $2.3 \% \mathrm{Au}-5.0 \% \mathrm{ZnO} / \mathrm{Al}_{2} \mathrm{O}_{3}, 5.0 \% \mathrm{ZnO} / \mathrm{Al}_{2} \mathrm{O}_{3}$ and $2.3 \% \mathrm{Au} / \mathrm{Al}_{2} \mathrm{O}_{3}$, were characterized by BET, XRD, TEM, $\mathrm{H}_{2}$-TPR and IRAS, for component validation and interaction investigation purposes.

The specific surface area of $2.3 \% \mathrm{Au}-5.0 \% \mathrm{ZnO} / \mathrm{Al}_{2} \mathrm{O}_{3}, \quad 5.0 \% \mathrm{ZnO} / \mathrm{Al}_{2} \mathrm{O}_{3}$ and $2.3 \% \mathrm{Au} / \mathrm{Al}_{2} \mathrm{O}_{3}$ is $53.4,268.5$ and $458.2 \mathrm{~m}^{2} \cdot \mathrm{g}^{-1}$, respectively. Compared with the corresponding activities, specific surface area does not show strong correlation with the catalytic activity.

XRD patterns are presented in Fig. 4 , where the peak at $2 \theta=37^{\circ}$ corresponds to the typical pattern of Au species [42]. The results confirm that Au species only exist in (a) and (c). The peaks of $\mathrm{ZnO}$ species are not observable in the XRD patterns, suggesting that they are highly dispersed over the support and cannot be detected by XRD.

(Fig. 4 about here)

Fig. 5 shows the TEM images of the three catalysts. The particles on Au$\mathrm{ZnO} / \mathrm{Al}_{2} \mathrm{O}_{3}$ (Fig. 5(a)) and $\mathrm{Au} / \mathrm{Al}_{2} \mathrm{O}_{3}$ (Fig. 5(c)) had uniform size and distribution, while TEM image of $\mathrm{ZnO} / \mathrm{Al}_{2} \mathrm{O}_{3}$ (Fig. 5(b)) presents no observable particle. This is consistent with the XRD result, which indicates that the $\mathrm{ZnO}$ species were highly dispersed. In addition, the Au species were confirmed to be particles by TEM images.

(Fig. 5 about here)

Fig. 6 gives the TPR patterns. In the curves of $\mathrm{Au}-\mathrm{ZnO} / \mathrm{Al}_{2} \mathrm{O}_{3}$ and $\mathrm{ZnO} / \mathrm{Al}_{2} \mathrm{O}_{3}$, the peak around $510{ }^{\circ} \mathrm{C}$ corresponds to the reduction of $\mathrm{ZnO}$ [43] and the shift of peak was marginal. TPR patterns of $\mathrm{Au}-\mathrm{ZnO} / \mathrm{Al}_{2} \mathrm{O}_{3}$ and $\mathrm{Au} / \mathrm{Al}_{2} \mathrm{O}_{3}$ reveal that the peak around $300{ }^{\circ} \mathrm{C}$, corresponding to the reduction of gold species, shifts to lower temperature when $\mathrm{ZnO}$ is added. This peak shift phenomenon suggests the existence of significant interactions between $\mathrm{Au}$ and $\mathrm{ZnO}$.

(Fig. 6 about here) 
Results of IRAS are shown in Fig. 7. By comparing these three patterns, we suggest that the peaks between 2100 and $2200 \mathrm{~cm}^{-1}$ are part of the baseline, while the peak at $2060 \mathrm{~cm}^{-1}$ presents the absorbance strength of IR. Since the IR absorbance strength is proportional to the adsorption amount of $\mathrm{CO}$, the figure indicates that $\mathrm{Au}-\mathrm{ZnO} / \mathrm{Al}_{2} \mathrm{O}_{3}$ and $\mathrm{Au} / \mathrm{Al}_{2} \mathrm{O}_{3}$ present significantly stronger adsorption of $\mathrm{CO}$ than $\mathrm{ZnO} / \mathrm{Al}_{2} \mathrm{O}_{3}$. This observation confirms that $\mathrm{Au}$ is the active phase and adsorbs $\mathrm{CO}$ in the reaction. The higher absorbance strength of $\mathrm{Au}-\mathrm{ZnO} / \mathrm{Al}_{2} \mathrm{O}_{3}$ than that of $\mathrm{Au} / \mathrm{Al}_{2} \mathrm{O}_{3}$ indicates that $\mathrm{ZnO}$ promotes the $\mathrm{CO}$ adsorption capacity of $\mathrm{Au}$. This hypothesis has also been verified by the higher activity of $\mathrm{Au}-\mathrm{ZnO} / \mathrm{Al}_{2} \mathrm{O}_{3}$ during reactions, since the adsorption capacity of active phase is generally proportional to catalytic activity.

(Fig. 7 about here)

In summary, the characterization studies demonstrate that $\mathrm{Au}$ species are in particle form while $\mathrm{ZnO}$ species disperse uniformly over the support; there is significant interaction between $\mathrm{Au}$ and $\mathrm{ZnO}$, and the $\mathrm{CO}$ adsorption capacity of $\mathrm{Au}$ is significantly promoted by introducing $\mathrm{ZnO}$, resulting in improved activity for $\mathrm{CO}$ oxidation.

\section{Conclusions}

This paper presents a suite of computational tools, including HSS for space-filling DoE, GPR for modeling and EI for model-based optimization with uncertainty, to aid the development of high-performance catalysts for $\mathrm{CO}$ oxidation. These tools have been shown to be useful for catalyst screening, optimization and other related decision making (e.g. making a compromise between catalyst activity and cost). Finally, $2.3 \% \mathrm{Au}-5.0 \% \mathrm{ZnO} / \mathrm{Al}_{2} \mathrm{O}_{3}$ was successful identified for cost-effective low-temperature $\mathrm{CO}$ oxidation with a total of 21 experiments. Furthermore, XRD and TEM confirmed the form of chemical species in this catalyst. The other two characterization techniques, $\mathrm{H}_{2}$-TPR and IRAS, suggested the existence of significant interaction between $\mathrm{Au}$ and $\mathrm{ZnO}$. Adding $\mathrm{ZnO}$ clearly promotes the $\mathrm{CO}$ adsorption capacity of $\mathrm{Au}$, resulting in improved activity for $\mathrm{CO}$ oxidation.

In a broader perspective, the methodology of data-based modeling and optimization has seen a rapid development in recent years, and the proposed approach falls within this family. A rigorous and comprehensive assessment of current methods is clearly needed, and it will be pursued in the future.

\section{Acknowledgement}

Financial support from Singapore AcRF Tier 1 grant (RG 19/09) is acknowledged. Jiali Zhuo participated in the catalyst activity tests as a partial requirement of her final year project. 


\section{References}

[1] H. Zou, S. Chen, Z. Liu, W. Lin, International Journal of Hydrogen Energy 34 (2009) 9324-9333.

[2] H. Y. Kim, S. S. Han, J. H. Ryu, H. M. Lee, Journal of Physical Chemistry C 114 (2010) 3156-3160.

[3] N. Bion, F. Epron, M. Moreno, F. Marino, D. Duprez, Topics in Catalysis 51 (2008) 76-88.

[4] X. R. Chen, H. B. Zou, S. Z. Chen, X. F. Dong, W. M. Lin, Journal of Natural Gas Chemistry 16 (2007) 409-414.

[5] M. Hartmann, T. Kaltschmitt, O. Deutschmann, Catalysis Today 147 (2009) S204-S209.

[6] K. Qian, W. X. Huang, J. Fang, S. S. Lv, B. He, Z. Q. Jiang, S. Q. Wei, Journal of Catalysis 255 (2008) 269-278.

[7] W. Y. Yu, W. S. Lee, C. P. Yang, B. Z. Wan, Journal of the Chinese Institute of Chemical Engineers 38 (2007) 151-160.

[8] C. Y. Huang, Y. Y. Chen, C. C. Su, C. F. Hsu, Journal of Power Sources 174 (2007) $294-301$.

[9] G. Marban, I. Lopez, T. Valdes-Solis, A. B. Fuertes, International Journal of Hydrogen Energy 33 (2008) 6687-6695.

[10] G. Avgouropoulos, T. Ioannides, H. Matralis, J. Batista, S. Hocevar, Catalysis Letters 73 (2001) 33-40.

[11] T. Caputo, L. Lisi, R. Pirone, G. Russo, Applied Catalysis A-General 348 (2008) $42-53$.

[12] E. Moretti, M. Lenarda, L. Storaro, A. Talon, T. Montanari, G. Busca, E. Rodriguez-Castellon, A. Jimenez-Lopez, M. Turco, G. Bagnasco, R. Frattini, Applied Catalysis A-General 335 (2008) 46-55.

[13] E. Moretti, L. Storaro, A. Talon, P. Patrono, F. Pinzari, T. Montanari, G. Ramis, M. Lenarda, Applied Catalysis A-General 344 (2008) 165-174.

[14] R. H. Myers, D. C. Montgomery, Response Surface Methodology: Process and Product in Optimization Using Designed Experiments, John Wiley and Sons, Inc., 1995.

[15] Y. Chen, Z. Guo, T. Chen, Y. Yang, Journal of Catalysis 275 (2010) 11-24.

[16] K. Omata, Y. Kobayashi, M. Yamada, Energy and Fuels 23 (2009) 1931-1935.

[17] P. Serna, L. A. Baumes, M. Moliner, A. Corma, Journal of Catalysis 258 (2008) 25-34.

[18] Q. H. Tang, Y. T. Chen, C. Zhou, T. Chen, Y. H. Yang, Catalysis Letters 128 (2009) 210-220.

[19] D. Farrusseng, F. Clerc, C. Mirodatos, R. Rakotomalala, Computational Materials Science 45 (2009) 52-59.

[20] D. Farrusseng, F. Clerc, Applied Surface Science 254 (2007) 772-776.

[21] K. Omata, Y. Yamazaki, Y. Watanabe, K. Kodama, M. Yamada, Industrial and Engineering Chemistry Research 48 (2009) 6256-6261.

[22] S. Valero, E. Argente, V. Botti, J. M. Serra, P. Serna, M. Moliner, A. Corma, Computers and Chemical Engineering 33 (2009) 225-238.

[23] G. Grubert, S. Kolf, M. Baerns, I. Vauthey, D. Farrusseng, A. van Veen, C. Mirodatos, E. Stobbe, P. Cobden, Applied Catalysis A-General 306 (2006) 17-21.

[24] S. R. M. Pereira, F. Clerc, D. Farrusseng, J. C. van der Waal, T. Maschmeyer, Combinatorial Chemistry and High Throughput Screening 10 (2007) 149-159.

[25] J. Horiguchi, S. Kobayashi, Y. Yamazaki, T. Nakanishi, D. Itabashi, K. Omata, M. Yamada, Applied Catalysis A-General 377 (2010) 9-15.

[26] A. G. Maldonado, G. Rothenberg, Chemical Society Reviews 39 (2010) 1891-1902.

[27] J. Procelewska, J. L. Galilea, F. Clerc, D. Farrusseng, F. Schueth, Combinatorial Chemistry and High Throughput Screening 10 (2007) 37-50.

[28] G. Rothenberg, Catalysis Today 137 (2008) 2-10.

[29] J. R. Kalagnanam, U. M. Diwekar, Technometrics 39 (1997) 308-319.

[30] Q. Tang, Y. Lau, S. Hu, W. Yan, Y. Yang, T. Chen, Chemical Engineering Journal 156 (2010) 423-431.

[31] J. Yuan, K. S. Wang, T. Yu, M. L. Fang, International Journal of Machine Tools and Manufacture 48 (2008) 47-60. 
[32] D. R. Jones, Journal of Global Optimization 21 (2001) 345-383.

[33] S. Monyanon, S. Pongstabodee, A. Luengnaruemitchai, Journal of Power Sources 163 (2006) $547-554$.

[34] K. T. Fang, D. K. J. Lin, P. Winker, Y. Zhang, Technometrics 42 (2000) 237-248.

[35] M. D. McKay, R. J. Beckman, W. J. Conover, Technometrics 42 (2000) 55-61.

[36] X. Chen, F. R. Gao, Advances in Polymer Technology 25 (2006) 13-21.

[37] F. di Sciascio, A. N. Amicarelli, Computers and Chemical Engineering 32 (2008) 3264-3273.

[38] P. Zhou, F. F. Tian, X. Chen, Z. C. Shang, Biopolymers 90 (2008) 792-802.

[39] C. E. Rasmussen, C. K. I. Williams, Gaussian Processes for Machine Learning, MIT Press, 2006.

[40] J. Lin, S. Jang, Industrial and Engineering Chemistry Research 37 (1998) 3640-3651.

[41] M. Coleman, D. Block, AIChE Journal 53 (2007) 1496-1509.

[42] L. H. Chang, Y. W. Chen, N. Sasirekha, Industrial and Engineering Chemistry Research 47 (2008) 4098-4105.

[43] F.-W. Chang, S.-C. Lai, L. S. Roselin, Journal of Molecular Catalysis A-Chemical 282 (2008) 129-135.

Table 1: Catalyst components considered in the screening stage.

\begin{tabular}{|c|c|c|c|}
\hline Component & Component choice & Corresponding precursor & MW of precursol \\
\hline \multirow{4}{*}{ Active Phase } & $\mathrm{Au}$ & $\mathrm{HAuCl}_{4} \cdot 3 \mathrm{H}_{2} \mathrm{O}$ & 393.83 \\
\hline & $\mathrm{Ru}$ & $\mathrm{RuCl}_{3} \cdot \mathrm{nH}_{2} \mathrm{O}$ & 207.43 \\
\hline & $\mathrm{Pd}$ & $\mathrm{Cl}_{2} \mathrm{Pd} \cdot 2 \mathrm{HCl}$ & 250.32 \\
\hline & $\mathrm{Pt}$ & $\mathrm{H}_{2} \mathrm{PtCl}_{6} \cdot 6 \mathrm{H}_{2} \mathrm{O}$ & 517.90 \\
\hline \multirow{4}{*}{ Promoter } & $\mathrm{MnO}_{2}$ & $\mathrm{Mn}\left(\mathrm{NO}_{3}\right)_{2} \cdot 4 \mathrm{H}_{2} \mathrm{O}$ & 251.01 \\
\hline & $\mathrm{CuO}$ & $\mathrm{Cu}\left(\mathrm{NO}_{3}\right)_{2} \cdot 2.5 \mathrm{H}_{2} \mathrm{O}$ & 232.59 \\
\hline & $\mathrm{ZnO}$ & $\mathrm{Zn}\left(\mathrm{NO}_{3}\right)_{2} \cdot 6 \mathrm{H}_{2} \mathrm{O}$ & 297.48 \\
\hline & $\mathrm{MgO}$ & $\mathrm{Mg}\left(\mathrm{NO}_{3}\right)_{2} \cdot 6 \mathrm{H}_{2} \mathrm{O}$ & 256.41 \\
\hline \multirow{4}{*}{ Support } & $\mathrm{Al}_{2} \mathrm{O}_{3}$ & $\mathrm{Al}\left[\mathrm{OCH}\left(\mathrm{CH}_{3}\right)_{2}\right]_{3}$ & 204.25 \\
\hline & $\mathrm{Co}_{3} \mathrm{O}_{4}$ & $\left(\mathrm{C}_{5} \mathrm{H}_{8} \mathrm{O}_{2}\right)_{2} \mathrm{Co}$ & 257.15 \\
\hline & $\mathrm{TiO}_{2}$ & $\left(\mathrm{C}_{4} \mathrm{H}_{9} \mathrm{O}\right)_{4} \mathrm{Ti}$ & 340.50 \\
\hline & $\mathrm{SiO}_{2}$ & - & - \\
\hline
\end{tabular}


Table 2: Screening experiments designed by HSS.

\begin{tabular}{cccc}
\hline No. & Noble metal (loading, wt.\%) & Promoter (loading, wt.\%) & Support \\
\hline 1 & $\mathrm{Au} \mathrm{(1.8)}$ & $\mathrm{CuO}(1.6)$ & $\mathrm{Co}_{3} \mathrm{O}_{4}$ \\
2 & $\mathrm{Au} \mathrm{(2.6)}$ & $\mathrm{MnO}_{2}(2.1)$ & $\mathrm{TiO}_{2}$ \\
3 & $\mathrm{Au}(3.4)$ & $\mathrm{ZnO}(2.7)$ & $\mathrm{Al}_{2} \mathrm{O}_{3}$ \\
4 & $\mathrm{Ru}(4.2)$ & $\mathrm{ZnO}(3.9)$ & $\mathrm{Co}_{3} \mathrm{O}_{4}$ \\
5 & $\mathrm{Ru}(1.2)$ & $\mathrm{CuO}(4.4)$ & $\mathrm{SiO}_{2}$ \\
6 & $\mathrm{Ru}(2.0)$ & $\mathrm{MgO}(1.1)$ & $\mathrm{Al}_{2} \mathrm{O}_{3}$ \\
7 & $\mathrm{Pd}(2.8)$ & $\mathrm{MnO}(1.7)$ & $\mathrm{TiO}_{2}$ \\
8 & $\mathrm{Pd}(3.6)$ & $\mathrm{ZnO}(2.2)$ & $\mathrm{Al}_{2} \mathrm{O}_{3}$ \\
9 & $\mathrm{Pd}(4.4)$ & $\mathrm{CuO}(2.8)$ & $\mathrm{Co}_{3} \mathrm{O}_{4}$ \\
10 & $\mathrm{Pt}(1.3)$ & $\mathrm{MgO}(3.4)$ & $\mathrm{TiO}_{2}$ \\
11 & $\mathrm{Pt}(2.1)$ & $\mathrm{MnO}(3.9)$ & $\mathrm{Al}_{2} \mathrm{O}_{3}$ \\
12 & $\mathrm{Pt}(2.9)$ & & \\
\hline
\end{tabular}

Table 3: Further investigation on $\mathrm{Au}-\mathrm{ZnO} / \mathrm{Al}_{2} \mathrm{O}_{3}$ catalyst ( $y$ : actual activity; $\hat{y}$ : mean prediction from GPR).

\begin{tabular}{|c|c|c|c|c|}
\hline Step & Run No. & Composition & $y(\%)$ & $\hat{y}(\%)$ \\
\hline \multirow{3}{*}{ Initial } & 1 & $3.4 \% \mathrm{Au}-2.7 \% \mathrm{ZnO} / \mathrm{Al}_{2} \mathrm{O}_{3}$ & 95.9 & - \\
\hline & 2 & $1.0 \% \mathrm{Au} / \mathrm{Al}_{2} \mathrm{O}_{3}$ & 4.8 & - \\
\hline & 3 & $5.0 \% \mathrm{Au} / \mathrm{Al}_{2} \mathrm{O}_{3}$ & 91.8 & - \\
\hline \multirow{2}{*}{$\begin{array}{l}\text { Iterative } \\
\text { optimization }\end{array}$} & 4 & $4.9 \% \mathrm{Au}-5.0 \% \mathrm{ZnO} / \mathrm{Al}_{2} \mathrm{O}_{3}$ & 100.0 & 112.2 \\
\hline & - & $2.3 \% \mathrm{Au}-5.0 \% \mathrm{ZnO} / \mathrm{Al}_{2} \mathrm{O}_{3}$ & - & 45.9 \\
\hline \multirow{6}{*}{$\begin{array}{l}\text { Au-loading } \\
\text { reduction }\end{array}$} & 5 & $3.2 \% \mathrm{Au}-5.0 \% \mathrm{ZnO} / \mathrm{Al}_{2} \mathrm{O}_{3}$ & 100.0 & 98.2 \\
\hline & 6 & $2.8 \% \mathrm{Au}-5.0 \% \mathrm{ZnO} / \mathrm{Al}_{2} \mathrm{O}_{3}$ & 100.0 & 97.6 \\
\hline & 7 & $1.0 \% \mathrm{Au}-5.0 \% \mathrm{ZnO} / \mathrm{Al}_{2} \mathrm{O}_{3}$ & 3.5 & 95.3 \\
\hline & 8 & $2.5 \% \mathrm{Au}-5.0 \% \mathrm{ZnO} / \mathrm{Al}_{2} \mathrm{O}_{3}$ & 100.0 & 96.0 \\
\hline & 9 & $2.1 \% \mathrm{Au}-5.0 \% \mathrm{ZnO} / \mathrm{Al}_{2} \mathrm{O}_{3}$ & 80.8 & 95.9 \\
\hline & 10 & $2.3 \% \mathrm{Au}-5.0 \% \mathrm{ZnO} / \mathrm{Al}_{2} \mathrm{O}_{3}$ & 95.4 & 95.7 \\
\hline \multirow{2}{*}{$\begin{array}{l}\text { Interaction } \\
\text { investigation }\end{array}$} & 11 & $5.0 \% \mathrm{ZnO} / \mathrm{Al}_{2} \mathrm{O}_{3}$ & 1.5 & - \\
\hline & 12 & $2.3 \% \mathrm{Au} / \mathrm{Al}_{2} \mathrm{O}_{3}$ & 84.9 & - \\
\hline
\end{tabular}



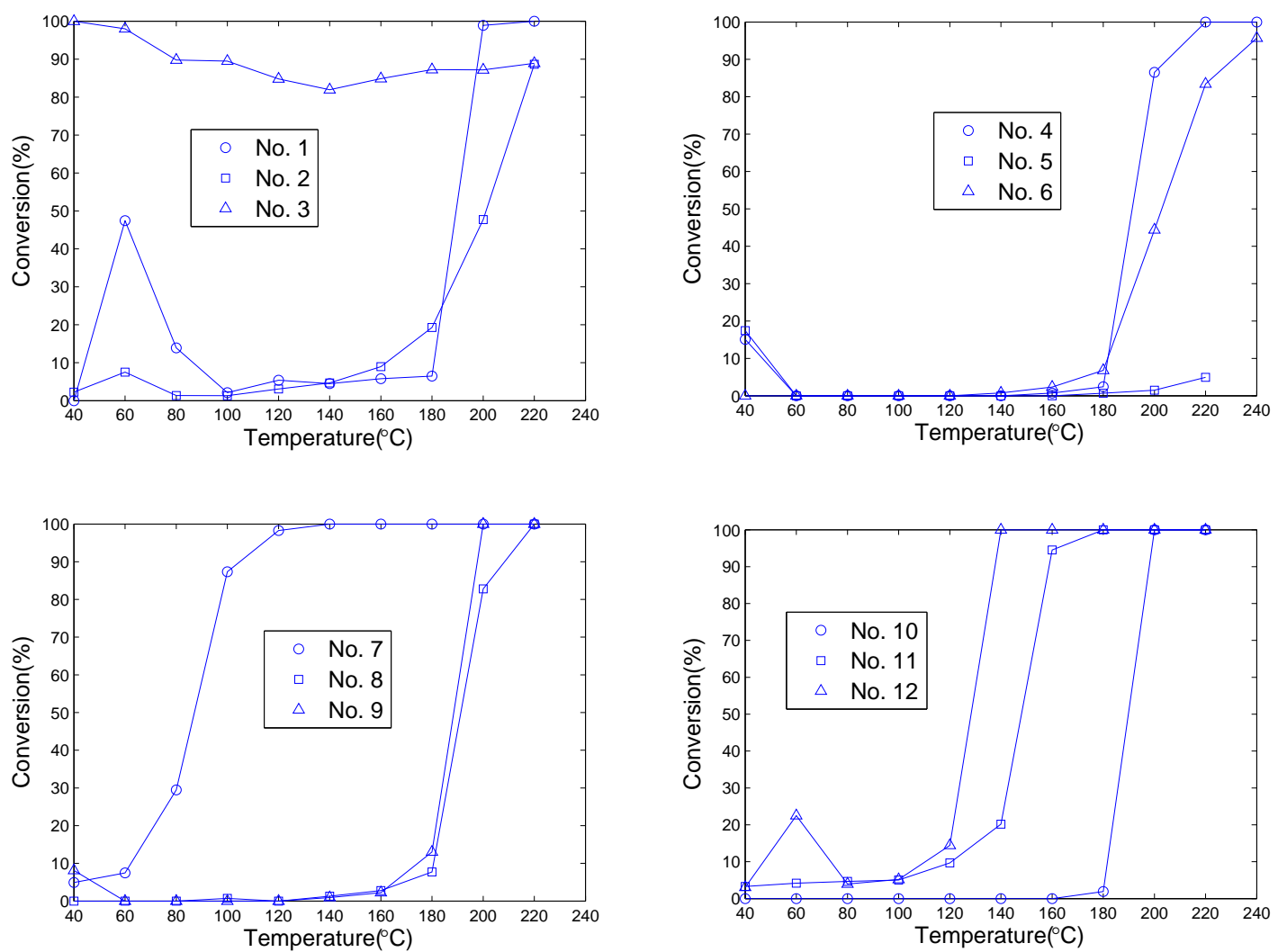

Figure 1: CO conversion versus temperature for the catalysts listed in Table 2 for screening. 


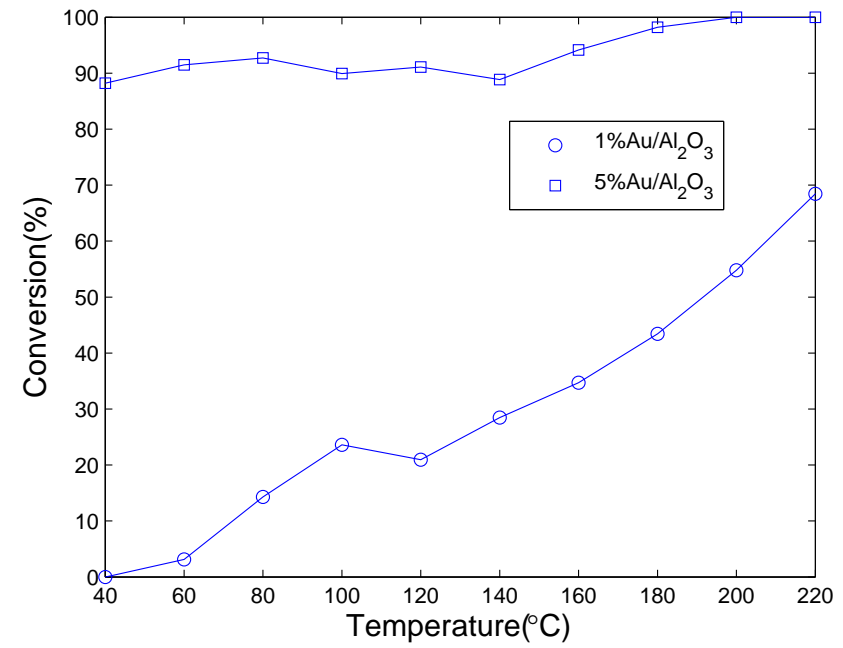

Figure 2: $\mathrm{CO}$ conversion versus temperature for two $\mathrm{Au} / \mathrm{Al}_{2} \mathrm{O}_{3}$ catalysts.

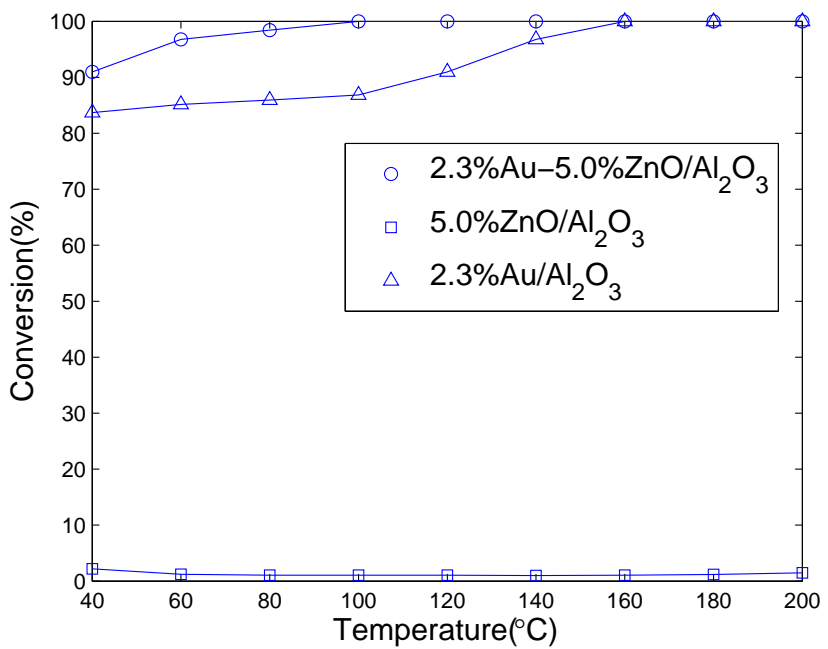

Figure 3: CO Conversion versus temperature for $\mathrm{Au}-\mathrm{ZnO} / \mathrm{Al}_{2} \mathrm{O}_{3}, \mathrm{ZnO} / \mathrm{Al}_{2} \mathrm{O}_{3}$ and $\mathrm{Au} / \mathrm{Al}_{2} \mathrm{O}_{3}$. 


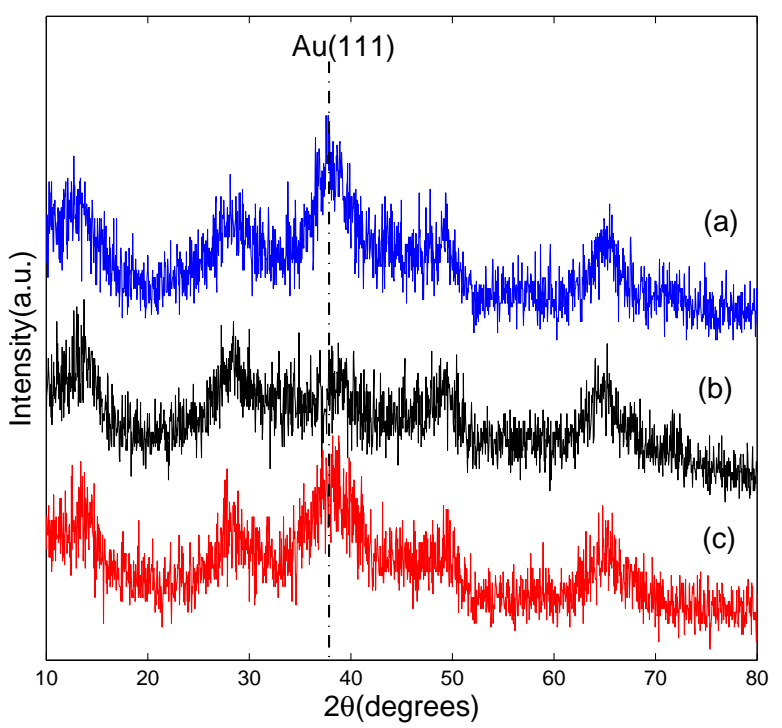

Figure 4: XRD pattern of (a) $\mathrm{Au}-\mathrm{ZnO} / \mathrm{Al}_{2} \mathrm{O}_{3}$, (b) $\mathrm{ZnO} / \mathrm{Al}_{2} \mathrm{O}_{3}$ and (c) $\mathrm{Au} / \mathrm{Al}_{2} \mathrm{O}_{3}$. 
(a)

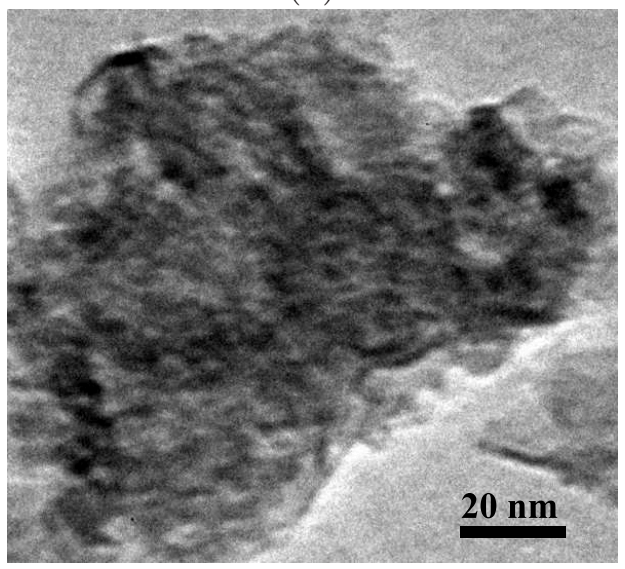

(b)

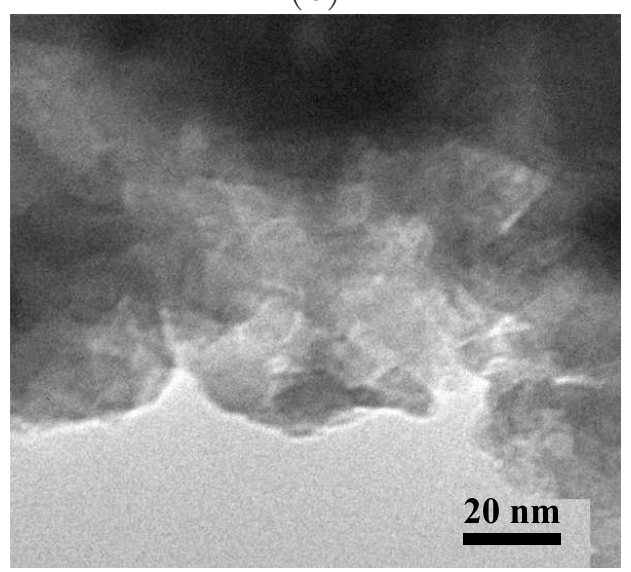

(c)

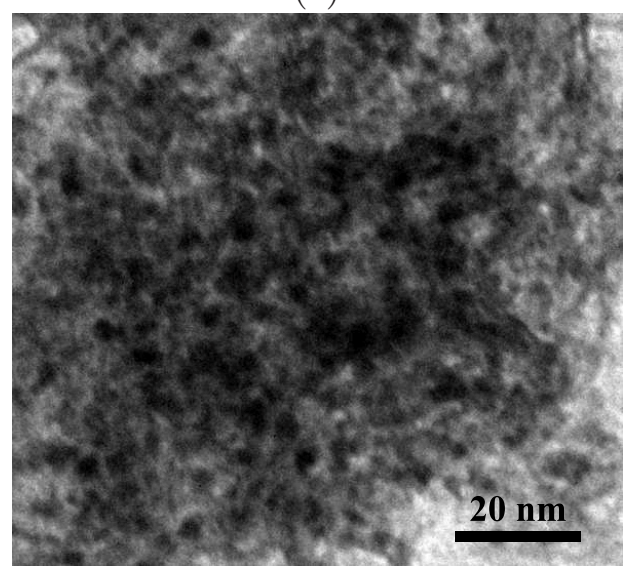

Figure 5: TEM image of (a) $\mathrm{Au}-\mathrm{ZnO} / \mathrm{Al}_{2} \mathrm{O}_{3}$, (b) $\mathrm{ZnO} / \mathrm{Al}_{2} \mathrm{O}_{3}$ and (c) $\mathrm{Au} / \mathrm{Al}_{2} \mathrm{O}_{3}$. 


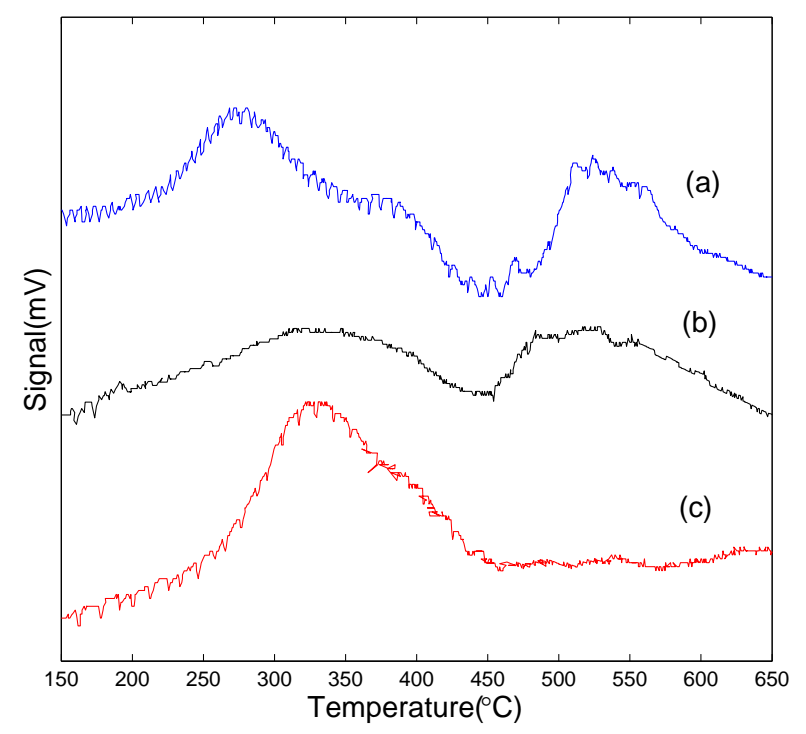

Figure 6: $\mathrm{H}_{2}$-TPR pattern of (a) $\mathrm{Au}-\mathrm{ZnO} / \mathrm{Al}_{2} \mathrm{O}_{3}$, (b) $\mathrm{ZnO} / \mathrm{Al}_{2} \mathrm{O}_{3}$ and (c) $\mathrm{Au} / \mathrm{Al}_{2} \mathrm{O}_{3}$.

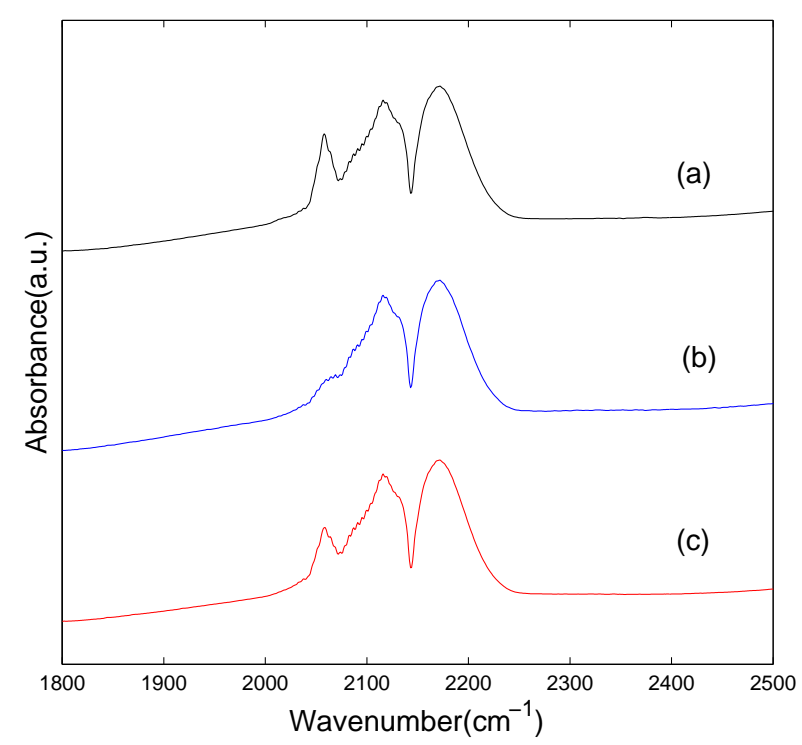

Figure 7: IRAS pattern of (a) $\mathrm{Au}-\mathrm{ZnO} / \mathrm{Al}_{2} \mathrm{O}_{3}$, (b) $\mathrm{ZnO} / \mathrm{Al}_{2} \mathrm{O}_{3}$ and (c) $\mathrm{Au} / \mathrm{Al}_{2} \mathrm{O}_{3}$. 